\title{
Toward a conceptualization of the online shopping experience
}

\author{
Aurélia Michaud Trevinal ${ }^{\mathrm{a}, *}$, Thomas Stenger ${ }^{\mathrm{b}, 1}$ \\ a University Institute of Technology, University of La Rochelle, 15 rue F. de Vaux de Foletier, Lab. CEREGE, EA-1722, 17 000 La Rochelle, France \\ ${ }^{\mathrm{b}}$ Institute of Business and Management (IAE), University of Poitiers, 20, rue Guillaume VII le Troubadour, Lab. CEREGE, EA-1722, BP 639-86022 \\ Poitiers Cedex, France
}

\section{A R T I C L E I N F O}

\section{Article history:}

Received 13 June 2013

Received in revised form

24 January 2014

Accepted 20 February 2014

Available online 20 March 2014

Keywords:

Shopping

Experience

Online

Consumption

Appropriation

Facebook

\begin{abstract}
A B S T R A C T
This research article explores the content of consumers' experience when they shop online and proposes a first step in conceptualizing the 'online shopping experience' (OSE). First, we carried out an extended literature review and proposed an integrative conceptual framework. Then, we relied on a consumers discourse analysis with four focus groups with consumers who differ in terms of age, gender and online shopping experience.

We define the OSE and propose a conceptualization through four core dimensions: the physical, ideological, pragmatic and social dimensions. Connections are established between the flow concept and the 'traditional' dimensions of experience, and specific shopping values are identified. Moreover, an appropriation process of commercial websites is revealed; beyond purchase intentions and rituals, the OSE is embodied by the use of online tools and patronage routines. Finally, social interactions with Facebook friends are one of the new practices considered.
\end{abstract}

(c) 2014 Elsevier Ltd. All rights reserved.

\section{Introduction: what is the content of consumers' experience when they shop online?}

The nature of consumption experience is established as the interaction in a situation - in a place and during a period of time between an individual and an object (Arnould and Thomson, 2005). A four-stage process has been proposed to represent the customer experience (Arnould et al., 2004), which distinguishes the core of the experience from the anticipated experience and from the purchase itself, in addition to differentiate it from memories and nostalgia. The shopping experience is allencompassing (Arnould et al., 2004); consumers may experience it in many ways that depend on the social context, on the products and services for which they are shopping and on the personal relationships that help form the situation (Edgell et al., 1997).

Considering the amount of literature dedicated to consumption experience, shopping experience and the latest development in e-marketing and e-tailing, this paper seeks to improve our understanding of shopping experience in the online context. A holistic empirical examination of the experience concept is also proposed.

\footnotetext{
* Corresponding author. Tel.: +33 5465139 57; fax: +33 546513918 .

E-mail addresses: amichaud@univ-lr.fr (A. Michaud Trevinal), stenger@iae.univ-poitiers.fr (T. Stenger).

URLS: http://aureliamichaud.wordpress.com/ (A. Michaud Trevinal), http://thomasstenger.kiubi-web.com/ (T. Stenger).

${ }^{1}$ Tel.: + 33549454499 .
}

Some approaches focus on isolated elements such as brand (Brakus et al., 2009) or in-store experience (Arnold et al., 2005). The shopping experience has been studied in retailing research with a focus on a 'recreative' type of consumer and on the enjoyment derived from shopping (Bäckström, 2011); the shopping experiences should be either cultural (as in a museum) or "spectacular" at Nike Town (Carù and Cova, 2007). A few specific online experiences have been investigated, like those in services (Jüttner et al., 2013) or in online communities (Nambisan and Watt, 2011). Extended research has provided considerable evidence that help to characterize the flow experience (Hoffman and Novak, 2000, 2009), or to identify antecedents and outcomes of online experiences (Rose et al., 2012).

This research does not address the antecedents or outcomes of online shopping experience (OSE); this study rather focuses on the conceptualization of the OSE itself, that is to say, on what comprises the entire OSE. Online consumer experience encompasses much more than e-purchase experience or the positive experience created by the e-tailer.

Are the varied aspects and concepts of consumption and shopping maintained in the online context? Are they sufficient to describe the OSE?

The purpose of this research is to expand and deepen the present state of the art of the OSE. The main objectives of the research are to:

(1) Identify the dimensions and components of the OSE. 
(2) Develop a comprehensive theoretical framework of OSE that incorporates OSE component variables based on pre-existing theory of consumption, shopping and online experience.

Therefore, this paper raises the following questions: What is the content of the specific experience lived during the OSEs? What do consumers experience when they shop online?

By pursuing these objectives, this paper makes several contributions to the e-marketing and retailing literature that both brings new knowledge and extends existing knowledge, developing a conceptualization of OSE not to be found in the literature.

This paper is structured as follows. First, we will review the literature about the consumption and shopping experiences as well as online experience. Second, we will consider how these elements could fit with the online context by designing a conceptual framework; we shall also present the data collection and data analysis procedures. Third, we will consider the four core dimensions of the OSEs and discuss their specific components and characteristics. Fourth, we will conclude and offer directions for future research.

\section{Literature review: consumption, shopping and online experience}

\subsection{Consumption experience}

The consumption experience extends beyond the consumption of products and services to encompass the consumption of events - baseball games, movies, rafting, etc. (Woodward and Holbrook, 2013). This may explain why the literature on consumption experience includes interpretative research on full-blown experience as well as the customer experience.

\subsubsection{A psychological dimension: cognitive and affective aspects of the experience}

The customer experience is conceptualized as a psychological construct composed of cognitive and affective aspects (Holbrook and Hirschman, 1982; Dubé and LeBel, 2003; Gentile et al., 2007; Brakus et al., 2009; Verhoef et al., 2009; Jüttner et al., 2013). Holbrook and Hirschman's (1982) groundbreaking research has examined the subjective dimension of consuming and the consumption experience as a psychological phenomenon. Their work emphasizes the emotional state taking place during the consumption process. Along with others components, the cognition and emotion-related components of the consumption experience have been identified as influential components of the formation process of the customer experience. ${ }^{2}$

\subsubsection{A physical and sensorial dimensions}

Nevertheless, the physical dimension, - in other words, the aspects of consumer behavior related to the multisensory side of the consumer experience - predominates (Addis and Holbrook, 2001; Holbrook and Hirschman, 1982). Indeed, the literature contends that the consumption experience is composed of a physical dimension related to physical participation in the environment and the specific relationship the individual is committed to (Pine and Gilmore, 1999). This dimension forms the tangible base of the experience. The experience is multi-sensory; an individual may see, touch, smell, taste, and feel the consumption object (Heilbrunn, 2010). The experience occurs in space and time;

\footnotetext{
${ }^{2}$ In the literature, the stimuli processed through thoughts and reasoning are referred to as "cognitive", "functional stimuli" (Berry et al., 2002), "rational" or "intellectual” (Brakus et al., 2009).
}

the consumer may choose, hesitate, reject and use the object. For Carù and Cova (2007), the core elements in the consumption experience are time pressure and the duration of experience. However, time is not reflected in the work of other scholars, whereas elements of place are cited. Indeed, along with the cognitive and affective components discussed previously, Verhoef et al. (2009) suggest that the customer experience is a physical nature. Their model suggests that the determinants of the customer experience include the social environment, service interface, the retail atmosphere, and range of products price. They state that the situation of CE (type of store, location) can moderate the overall CE.

\subsubsection{Values and rituals: the symbolic dimension of consumption}

The consumption experience promotes values and an imaginary world (Holbrook, 2000). Through consumption, consumers acquire and manipulate object meanings (Holt, 1995). The numerous processes of integration and classification that were synthesized in Holt's research (1995) underline the symbolic dimension of consumption.

These processes may be the search for identity and self-image (Firat and Dholakia, 1998). They may be producing or personalizing processes like rituals (Holt, 1995). There are numerous rituals in the consumer's everyday life that are but a few examples of the many consumption experiences (Rook, 1985; McCracken's, 1986). Rituals are actions and interactions characterized by a sequential process that is regularly repeated and that may have a symbolic dimension. In addition, there may be a sacralizing process in consumption (Belk et al., 1989). For instance, certain rituals are linked to the consumer's culture (Christmas, birthday, etc.) and may be considered as scripts for an experience that is socially accepted (Wallendorf and Arnould, 1991). Therefore, in rituals - be they daily or irregular, extra-ordinary or ordinary ones - individuals save time and communicate values to other people (Goffman, 1974).

\subsubsection{Consumption as a pragmatic experience}

Previous research on consumption has also considered the practices of consumers as being part of the experience. Indeed, like the various practices listed by Holt (1995) during a baseball game, the experience may be defined by a precise set of acts and gestures by which consumers make the consumption object their own (Heilbrunn, 2010).

The acts that are realized during the experience underline the role of the consumer in the experience or in the co-production of the experience (Pine and Gilmore, 1999; Schmitt, 1999). Thus, consumer behavior reveals more than a functional use of products and services; behaviors are the expression of the appropriation of the environment by the consumer (Fischer, 1997). In the case of bank services, for example, the consumer can create new meanings and unusual functions while experiencing service that might increase the chances of improving service management (AubertGamet, 1997). In their research on brand experiences, Brakus et al. (2009) have distinguished a behavioral response to stimuli. Such actions and bodily experiences are key elements of the experience. Gentile et al. (2007) have also added a pragmatic component in their empirical research with actual brands (i.e. experiences resulting from the practical act of doing something and usability). They did not, however, empirically test the model.

The theoretical perspective of environmental sociology considers the individual as no longer reactive; s/he becomes a coproducer of the environment. The self-sufficient individual is free to test and tamper with the available elements (De Certeau, 1984). The individual is intent on participating in the experience, extraordinary or not, because s/he wants to be part of the experimentation 
(De Certeau, 1984). The consumer appropriates his everyday life by conducting his own experiment in which he may have control of the situation (Hui and Bateson, 1991). In the most recent literature on customer service experiences, the experience is co-created by nature (Jüttner et al., 2013).

\subsubsection{The social and relational dimension of consumption experience}

Holt's typology of consumption practices (1995) develops the interpersonal dimension of consuming, which describes how consumers use objects to interact with other consumers.

More recently, Gentile et al. (2007) have distinguished in relational component of the customer experience, notably experiences emerging from social contexts and relationships, that occurs during common consumption as part of a real or imagined community or to assert one's social identity.

\subsection{The shopping experience}

\subsubsection{Retail environment and in-store experience: sensory aspects,} emotions and social connections

As far as shopping is concerned, the sensitive aspects are of great significance (Babin and Attaway 2000). In the retail setting, imagery and sensory elements of the shopping experience elicit enjoyment, esthetic pleasure, and value for the consumer (Holbrook, 2006). Previous studies demonstrate the importance of sensory experiences and their role in the retail setting (Fiore and Kim, 2007), or they focus on the antecedents and consequences of in-store experiences on impulse buying (Yoon, 2013). Emotions associated with the shopping outcomes are underlined (Machleit and Eroglu, 2000; Arnold et al., 2005; Andreu et al., 2006); furthermore, retail customer experience has been described with a focus on positive emotions (Hui and Bateson, 1991; Bagdare and Jain, 2013). Finally, there is a consensus in the retailing literature on the store as experience place, and the role of the store as an experience environment allowing sensory, emotional and social connections (Verhoef et al., 2009; Spena et al., 2012).

\subsubsection{Values and symbols of shopping}

During a shopping trip, customers form value perceptions on the basis of their interaction with the products and with the various aspects of the store (e.g. location, staff, and environment) (Albrecht, 1995), such as the manner in which front-of-store employees deliver service (Sweeney et al. 1999) or the tangible products themselves (Sweeney and Soutar, 2001). The overall shopping experience may contribute to the hedonistic or utilitarian shopping value (Babin et al. 1994).

Furthermore, the shopping experience may have a symbolic signification, such as with River Magic, a multi-day commercial river rafting that is experienced and lived by consumers as a pilgrimage, a communion with nature (Arnould and Price, 1993). However, if the stream of research referred to as CCT, which concerns the dynamic nature of shopping, has been successful in relating peak-experiences as well as the leisure shopping (Bäckström, 2011), there is still a need for more thorough investigations of the overall shopping experience.

\subsubsection{The social dimension of shopping}

Beginning with the seminal research of Tauber (1972), marketing research provides considerable evidence that suggests that shopping is a social experience. Indeed, since the 19th century described in Zola (1883), stores have been places where consumers could go with friends, where mothers and daughters might socialize with other mothers and daughters, and where it was possible to chat and live a social experience.
As discussed in Borges et al. (2010), a social companion may enhance shopping emotions and create a more hedonistically oriented shopping experience. A companion can also provide advice and encourage social exchange with others. The influence of community and identification on consumers' shopping intentions and behavior is also noticeable. As a matter of fact, consumers prefer to shop in stores where they think they will find other consumers who are similar to them, which indicates a high level of identification (Chebat et al., 2006). Another element is proximity with providers. In examining service encounters, Price et al. (1995) note that spatial proximity and the proxemics between customers and service providers positively affect the overall evaluation of service encounters; intimate proxemics heighten involvement and attachment.

\subsection{Customer experience in online environments}

\subsubsection{A flow experience?}

The flow model proposed by Hoffman and Novak (1996; 2009); (Novak et al., 2000; Novak et al., 2003) is of particular interest. Although these authors contended in 2009 that the concept of flow was still ambiguous and difficult to measure and model, it is nevertheless enriching.

First, the central hypothesis of the model is that the online environment is interactive by nature; consumers interact with websites, with other consumers and with the interface itself. Flow is conceptualized as "the state occurring during network navigation, which is (1) characterized by seamless sequence of responses facilitated by machine interactivity, (2) intrinsically enjoyable, (3) accompanied by a loss of self-consciousness, and (4) selfreinforcing" (1996, p. 57). From the consumer's perspective, "concentration on the navigation experience is so intense that there is little attention left to consider anything else, " and "selfconsciousness disappears, the consumer's sense of time becomes distorted and the state of mind arising from achieving flow on the web is extremely gratifying" (2000, p. 24).

In this perspective, the flow model seems to be a navigation model rather than a customer experience one. The opinions of these authors on this matter have evolved over time. In their latest article, they consider that the flow model is "a conceptual model of the network navigation process for Web users" (2009, p. 24). Finally, flow can occur for both experiential and goal-directed activities (Novak et al., 2003), including those that involve product information search (Mathwick and Rigdon, 2004). In this case, when operating in a flow state, users become enjoyably immersed in the online activity to the point that it is transformed into an act of play (idem).

\subsubsection{Values in online customer experience}

Concerning the other aspects of the experience in the online context, previous studies have stressed values. Indeed, the retail environment delivers memorable, relevant and valued experiences on the Internet and through multi-channel retail systems (Mathwick et al., 2001). The dichotomy hedonic/utilitarian shopping value is also considered in the e-marketing literature (Mathwick and Rigdon, 2004; Novak et al., 2003; Nambisan and Watt, 2011; Stenger, 2011a).

Lemke et al. (2011) adopt a value-in-use approach to understand customer experience in which it is co-created by an alignment between the customer's goals and an organization's offering. Given the nature of Web 2.0 technology, virtual environments may be places where the customer and retailer jointly co-create experiences (Kohler et al., 2011; Rose et al., 2012). 


\subsubsection{The social dimension of online experience}

Online, the social dimension has been largely highlighted within virtual/online communities of consumption (Kozinets, 2002; Kozinets et al., 2008; Füller et al., 2007; Nambisan and Watt, 2011) and brand communities (Muniz and O'Guinn, 2011; Schau et al., 2009), especially on new social media platforms such as socio-digital networks (Zaglia, 2013; Stenger and Coutant, 2013). A whole spectrum of online social experiences has been pointed out by Pentina et al., (2011), which comprises interactions with the important referents through the web site (e.g. wish list, email-a-friend feature), customer involvement with other shoppers (reading other customers' reviews and checking product ratings) and connecting with friends via socio-digital networks.

Recent academic works dedicated to social media generally reinforced the role of the social dimension in the Internet users' online experience (Michaud-Trévinal and Stenger, 2012; Stenger, 2011b). But one can also notice that, until now, it is the consumption experience - talking, sharing about consumption and product/service use - rather than the shopping experience that has been put forward in the literature.

\section{Conceptual framework and methodology: analyzing the OSE through consumers' discourse analysis}

The extended literature review carried out above highlights a wide diversity in the conceptualization of the experiences - consumption, shopping and online customer experiences (Table 1). Six categories which were not treated equally in the literature, have been identified. The cognitive and affective states as well as the values, symbols and rituals experienced by the consumers have been widely referenced; the social aspect has been underlined as well, while the sensoryphysical aspect has only been highlighted for off-line experiences; the pragmatic aspects of the experience are only assumed in the consumption literature and the flow is only considered in the online consumer experience literature. This drives us to design an integrative conceptual framework to conceptualize the online shopping experience based on four major dimensions (Table 2).

\subsection{Conceptual framework}

First, as in the offline context, the OSE may be constituted of a physical dimension. In the online context, this may refer to the time/duration of the shopping experience and to the sensory dimension of the consumer with the commercial website and the shopping place.

Second, values and symbolic significations may also be part of the OSE. They compose an ideological dimension of the OSE that relates to the ability of the online shopping environment to promote values and build an imaginary world.

Third, a practice-based or pragmatic dimension may be considered using the following two aspects that are potentially constitutive elements of the OSE. On the one hand, the acts and gestures related to the use of online tools and all the shopping practices that structure the routines of shopping; on the other hand, the appropriation of online environment through such routines.

Finally, the social dimension, which is so important in traditional shopping experience, may also be part and parcel of the OSE.

The cognitive and affective aspects of the experience are not specific to a single dimension but constitutive of numerous ones. As a consequence, they have been integrated in the four dimensions of the conceptual framework. For instance, esthetics and value-in-use which are part of a psychological or cognitive state of the experience in the literature have been integrated in the physical dimension (as far as esthetic is concerned, through atmospheric and environment variables) and in the ideological dimension (for shopping values). The control and coproduction aspects, previously in the same large psychological category, are constitutive of the pragmatic dimension.

In the same manner, the flow concept is composed of three elements of the flow experience which may be considered as potentially constitutive of the OSE: the loss of self-consciousness, time distortion and the sensation of pleasure/gratification. Finally, the flow may mainly impact the physical dimension evoked above, through time and senses perceptions, and the ideological dimensions through pleasure and gratification.

\subsection{Method}

In this research, the nature of the OSE is thoroughly questioned; this study aims to conceptualize the OSE by exploring consumer discourses. Conceptual and qualitative research is a classic means of exploring shopping and online experience. For example, Tauber's

Table 1

A literature review: a synthesis on consumption, shopping and online experiences.

\begin{tabular}{|c|c|c|c|}
\hline Consumption experience & Shopping experience & Online customer experience & Main aspects and concepts \\
\hline $\begin{array}{l}\text { Brakus et al. (2009), Dubé and LeBel (2003), Gentile } \\
\text { et al. (2007), Holbrook and Hirschman (1982), } \\
\text { Jüttner et al. (2013) }\end{array}$ & $\begin{array}{l}\text { Bagdare and Jain (2013), Yoon } \\
\text { (2013), Verhoef et al. (2009) }\end{array}$ & $\begin{array}{l}\text { Hoffman and Novak (1996, 2009), } \\
\text { Pentina et al. (2011), Rose et al. (2012) }\end{array}$ & $\begin{array}{l}\text { Affective, emotions, } \\
\text { cognitive, psychological }\end{array}$ \\
\hline $\begin{array}{l}\text { Carù and Cova (2007). Heilbrunn (2010), Pine and } \\
\text { Gilmore (1999) }\end{array}$ & $\begin{array}{l}\text { Babin and Attaway (2000), } \\
\text { Verhoef et al. (2009) }\end{array}$ & Novak, Hoffman and Yung (2000) & Physical, sensorial \\
\hline $\begin{array}{l}\text { Arnould and Price (1993), Belk et al. (1989), } \\
\text { Goffman (1974), Heilbrunn (2010), Holbrook } \\
\text { (2000), Holt (1995), Mc Cracken (1986), Rook } \\
\text { (1985), Wallendorf \& Arnould (1991) }\end{array}$ & $\begin{array}{l}\text { Babin et al. (1994), Holbrook } \\
(1982,2000,2006)\end{array}$ & $\begin{array}{l}\text { Mathwick et al. (2001), Mathwick, Rigdon } \\
\text { (2004), Novak, Hoffman and Duhacheck } \\
\text { (2003), Nambisan and Watt (2011), Bridges } \\
\text { and Florsheim (2008) }\end{array}$ & Values, symbols, rituals \\
\hline $\begin{array}{l}\text { Aubert-Gamet (1997), Brakus et al. (2009), De } \\
\text { Certeau (1984), Gentile et al. (2007), Heilbrunn } \\
\text { (2010), Holt (1995), Hui and Bateson (1991), } \\
\text { Schmitt (1999) }\end{array}$ & & & Pragmatic, practice-based \\
\hline \multirow[t]{2}{*}{$\begin{array}{l}\text { Carù and Cova (2007), Gentile et al. (2007), } \\
\text { Holt (1995) }\end{array}$} & $\begin{array}{l}\text { Borges et al. (2010), Chebat et al. } \\
\text { (2006), Edgell et al. (1997), Price } \\
\text { et al. (1995), Rompay et al. (2012), } \\
\text { Tauber (1972), Verhoef et al. (2009) }\end{array}$ & $\begin{array}{l}\text { Hoffman and Novak (1996, 2009), } \\
\text { Nambisan and Watt (2011), Pentina et al. } \\
\text { (2011). }\end{array}$ & Social \\
\hline & & $\begin{array}{l}\text { Hoffman and Novak (1996, 2009), } \\
\text { Novak, Hoffman and Yung (2000), Novak, } \\
\text { Hoffman and Duhacheck, (2003), Mathwick } \\
\text { and Rigdon (2004) }\end{array}$ & Flow \\
\hline
\end{tabular}


Table 2

Conceptual framework of the online shopping experience (OSE).

\begin{tabular}{|c|c|c|}
\hline Dimensions & Components & Characteristics \\
\hline \multirow[t]{2}{*}{ Physical dimension } & Place and senses & $\begin{array}{l}\text { - Atmospherics (environment variables) } \\
\text { - Loss of self-consciousness }\end{array}$ \\
\hline & Time & $\begin{array}{l}\text { - Time distortion } \\
\text { - Time pressure/duration of experience }\end{array}$ \\
\hline \multirow[t]{3}{*}{ Ideological dimension } & Shopping values & $\begin{array}{l}\text { - Hedonic (sensation of pleasure and gratification) } \\
\text { - Utilitarian }\end{array}$ \\
\hline & Symbolism & $\begin{array}{l}\text { - Symbols in consumption } \\
\text { - Symbols in shopping }\end{array}$ \\
\hline & Rituals & $\begin{array}{l}\text { - Rituals in consumption } \\
\text { - Rituals in shopping }\end{array}$ \\
\hline \multirow[t]{2}{*}{ Pragmatic dimension } & Acts and gestures & $\begin{array}{l}\text { - Shopping practices } \\
\text { - Routines }\end{array}$ \\
\hline & Appropriation of the environment & $\begin{array}{l}\text { - Freedom } \\
\text { - Control } \\
\text { - Coproduction }\end{array}$ \\
\hline Social Dimension & Socialization & $\begin{array}{l}\text { - Companions: friends, peers, family } \\
\text { - Vendors }\end{array}$ \\
\hline
\end{tabular}

Table 3

31 people interviewed through 4 focus groups (details).

\begin{tabular}{|c|c|c|}
\hline Focus groups & First name (initials), age, activity and gender & Use of commercial sites \\
\hline FG no1:6 members & Ulrike (woman) 38 - marketing & Very intensive \\
\hline \multirow{4}{*}{5 women from 38 to 61 years old } & Monique (woman) 61 - retired & Regular \\
\hline & Nicole (woman) 59 - executive in a school & Regular \\
\hline & Stéphane (man) 40 - broker & Limited \\
\hline & 'Sidonie (woman) 39 - optician & Frequent \\
\hline 1 man - 40 years old & Marie-Laurence (woman) 39 - teacher & Frequent \\
\hline FG no2:10 members & Virginie (woman) 31 - unemployed engineer & Intense \\
\hline \multirow[t]{7}{*}{ 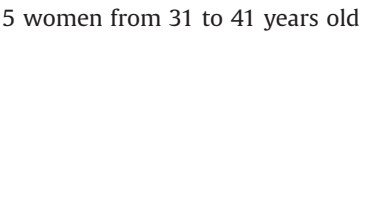 } & Coralie (woman) 36 - marketing & Very intensive \\
\hline & Gilles (man) 37 - executive in a local community & Intense \\
\hline & Karine (woman) 39 - Human Resource Director & Frequent \\
\hline & David 39 - senior police officer & Frequent \\
\hline & Marie (woman) 41 - psychologist & Regular \\
\hline & Christophe (man) 45 - engineer & Frequent \\
\hline & Thierry (man) 63 - retired teacher & Limited \\
\hline 5 men from 37 to 63 years old & Anne-Dominique (woman) 32 - manager of a pub & Frequent \\
\hline FG no3: 8 students & Marie-Haud (woman) 19 & Very intensive \\
\hline$\overline{\text { (1st degree University) }}$ & Carole (woman) 19 & Regular \\
\hline 6 female -19 years old & Sophie (woman) 19 & Regular \\
\hline \multirow[t]{5}{*}{2 men - 19 and 20 years old } & Lucie (woman) 19 & Frequent \\
\hline & Manon (woman) 19 & Regular \\
\hline & Camille (woman) 20 & Limited \\
\hline & Jonathan (man) 19 & Limited \\
\hline & Jordan (man) 20 & Limited \\
\hline FG no4: 7 students & Joana (woman) 18 & Regular \\
\hline (1st degree University) & Nancy (woman) 19 & Very intensive \\
\hline \multirow[t]{4}{*}{4 female from 18 to 19 years old } & Aurélie (woman) 19 & Frequent \\
\hline & Fiona (woman) 19 & Frequent (but no purchase) \\
\hline & Arnold (man) 19 & Regular \\
\hline & Florent (man) 19 & Limited \\
\hline 3 men from 19 to 20 years old & Benoît (man) 20 & Limited \\
\hline
\end{tabular}

seminal article (1972) is based on the interviews of thirty people, and Pace's analysis on online flow experience (2004) is based on semi-structured, in-depth interviews that focus on building rather than testing a theory. The constituent constructs can be tested subsequently (e.g., Hoffman and Novak, 2009). Because of the exploratory nature of this research, a qualitative research methodology has been chosen; thirty-one people were interviewed in four focus groups. The sampling of these people does not claim to be 
statistically representative; instead, it comprises a theoretical sampling whose value derives from its diversity and conceptual exploration (Corbin and Strauss, 2008).

Two focus groups were conducted with consumers 31-63 years of age. There were 16 people total, among whom 6 males and 10 females in different professions. To situate the online shoppers socially and culturally, 2 other focus groups were conducted with undergraduate students aged between 18 and 20 years old; there were 15 respondents ( 5 male and 10 female). All had the same degree (see Table 3). Indeed, the homogeneity of these groups in terms of the age/activity of the participants may have offered participants an environment in which they believe they are free to share their experiences in the presence of similar people of the same socioeconomic background. This methodology may have served to facilitate conversation and dialog between the different participants in the study (Moisander et al., 2009).

The focus groups met on the 13th of August, 4th of September, 15th of October and 24th of October 2010. A three-part guide was created; after an introduction that presented the rules of the focus group and the moderator, the primary discussion topic focused on the temporality of practices and location. The second discussion topic stressed on the choice of websites, and the third on the behaviors during the shopping process. Each focus group was video recorded ( 2 video cameras) and their interviews were integrally transcripted, totalizing 92 pages, that is, 3147 lines.

A content analysis was then conducted to explore in detail the online shopping environment, website uses, practices and feelings during the OSE. The analysis began with coding every verbatim account utilizing a grid analysis recalling the four main dimensions and sub-dimensions (i.e., components and characteristics) of our conceptual framework as summarized in Table 1. If specific attention is paid to these four dimensions, we have also been very careful to devise potential new dimensions. The coding made it easier for us to identify known and new themes; open coding has also been employed when necessary - namely, for new themes such as the use of Facebook and for theme variations (Milesand Huberman, 1984; Corbin and Strauss, 2008). Finally, examples and themes were associated with dimensions and indexed in a broad table, which is the basis of the conceptual analysis.

\section{Results and discussion}

The results indicate that the four expected dimensions of the OSE have been found in the consumers' discourses, but with significant differences and specificities (Table 4). The proposed conceptual framework, as a whole, is relevant.

\subsection{Online shopping as a physical experience}

The physical dimension of the OSE relies on two main aspects; time management and distortion of the OSE on the one hand, and the web design and esthetics of the commercial websites on the other.

\subsubsection{Time distortion and time management}

Time distortion during the experience has often been evoked by the respondents: "I need time [to shop online]; I need time to look at everything". (Laura). Certain shoppers explain the tricks they use online: "You just click on it again and it is re-activated in twenty minutes; it gives me time to think about it, and then I reactivate again..." (Ulrike).

Time is not experienced the same way on the Internet; time may seems to pass slowly if consumers do not directly find what they need. The flow model discussed above (Hoffman and Novak, $1996,2009)$ pointed out this specific relationship to time distortion during online connection. The control over time during online information search, as expressed above by Ulrike or Marine, seems to be particularly appreciated by consumers. This result echoes Mathwick and Rigdon's argument, 2004 that the transfer of control to the consumer is the key to creating compelling online experiences. More specifically, it reveals the importance of the control over time (or time management) in positive OSE.

\subsubsection{Web design and esthetics}

The design influence and visual aspects of the websites were also mentioned: "Well, this site is 'flashy' and that changes my shopping behavior. Something in the structure of the site makes me behave differently" (Monique). "The ergonomics of the home page...some websites show the clothes from every angle" (Nicole). The role of avatars (Holzwarth et al., 2006) has never been expressed by respondents.

As far as the visual aspects of the commercial websites are concerned, the results underscore that these features have a significant role in generating trust and the perception of the quality guarantee that vendors may give to their consumers. This is consistent with previous research which insists on the role of visual priming and colors of the websites (Pelet and Papadopoulou 2012; Mandel and Johnson, 2002).

\subsection{Ideological dimensions of the OSE}

The ideological dimension of the OSE is mainly revealed through the shoppers' orientations (hedonistic/utilitarian), the values associated with online shopping and the rituals that the shoppers organize.

\subsubsection{Hedonistic/utilitarian orientations}

The shoppers indicate that they shop online because they want to treat themselves, because it is useful, or because they are looking for the best "value for money". "I buy a lot online but, as opposed to my husband, I do not buy useless things. I buy a lot of things... but useful things. I only buy useful things". (Marie). "For me, the internet entices me to buy!" (Ulrike). "Sometimes, you want to read a book, as if you were craving for food. It's something you want now! It's immediate!" (Monique). As noted in the literature (e.g., Babin et al. 1994; Bridges and Florsheim, 2008) and as we had previously expected, the consumers interviewed may have hedonistic or utilitarian reasons for shopping.

\subsubsection{Shopping values: privacy and political issues}

The results highlight another component of the ideological dimension of the OSE that refers to shopping values: trust and privacy issues as well as politics.

On the one hand, all the consumers interviewed spontaneously gave examples and metaphors of risk during the OSE.

The consumers indicate that they do not pay attention to the guarantees or the proof of trust the retailers may provide: "I even don't think about it! What on earth does it mean to check the website???" (Virginie). Web design and esthetics appear to be more efficient. This result is consistent with Bart et al. (2005) who found a number of site variables that affect consumer trust (in addition to the brand and fulfillment variables).

This study confirmed that privacy and security are important in site design but not as much as user-friendly navigation and presentation. All are key factors in site design, providing trust in vendors and reducing the consumer risk perceptions.

If the symbolic aspects of the OSE rely on well-known skepticism and risk aversion (Soopramanien, 2011), an unexpected difference in online shopping symbols is revealed according to 
Results: Dimensions, components and characteristics of the online shopping experience (OSE).

\begin{tabular}{|c|c|c|c|c|}
\hline Dimensions & Components & Characteristics & Selected verbatims & Contribution \\
\hline $\begin{array}{l}\text { Physical } \\
\text { dimension }\end{array}$ & Time & $\begin{array}{l}\text { - Time distortion: duration of } \\
\text { experience } \\
\text { - Time management }\end{array}$ & $\begin{array}{l}\text { - "When we are in front of our computer, time passes quickly" (Laurène). "We have } \\
\text { to think it over, because it [the computer he wants to buy online] costs a lot, so we } \\
\text { must spend a lot of time on it" (Jordan). "You need time to search [all the } \\
\text { websites]" (Sidonie). } \\
\text { - "If only I had a little time to go shopping downtown, I would probably spend } \\
\text { half the amount of money I actually spend per month!" (Ulrike) } \\
\text { "You need time to search around [all the websites]" (Sidonie). "I am not a } \\
\text { compulsive consumer: I wait and I wait until the product is sold at a discount" } \\
\text { (Marie-Haud). "I take my time; I know that if I only have } 5 \text { minutes between two } \\
\text { classes, it's not going to be sufficient; just looking quickly, I know that if I do that, }\end{array}$ & $\begin{array}{l}\text { New developing of time as a core component of the } \\
\text { physical dimension of OSE } \\
\text { Time distortion previously tested in the context of online } \\
\text { customer experience (Novak, Hoffman and Yung, 2000) } \\
\text { New developing of time management as part of OSE. } \\
\text { Loss consciousness was not verified as a characteristics } \\
\text { of OSE in this study }\end{array}$ \\
\hline
\end{tabular}

Senses
- Ergonomics and esthetics: architecture, website design website colors and ergonomics
- "Easy access is also really important! The first time we visit a site, if the friendly aspect!" (Karine). "The display! Now, I pay attention to that. For instance, physical dimension of OSE the display of the editor Le Manuscrit is crappy. You cannot get out of there! it is Place was not verified as a characteristics of OSE in this very interesting but you cannot escape [. ] Another example is the site that sells study very expensive trips but sometimes with $70 \%$ discount, five star hotels, the homepage is user-friendly. Well, only the front page is clean, because if you browse the site, it is not as appealing, it is so-so but at the beginning it is pleasant! (Monique).

- "The site is nice, it's attractive". (Sidonie). "Well, this site is flashy and that changes my shopping behavior. Something in the structure of the site makes me behave differently" (Monique). "A bag has to be shown on the girl's hand [...] I couldn't buy it if there wasn't the model!" (Ulrike). "It is very important that the product may be emphasized." (Nicole). The physical aspect is important for me; I never browse for clothes online: it isn't worthwhile, because in the end the design, and even the color, won't be the same" (Carole). "The ergonomics of the front-page. some websites show the clothes from every angle" (Nicole). "The site has to catch some websites show the clothes from every angle "(Nicole). "The site has to catch the eye, and then, it has to be easy to use". (Sidonie). "The vision is reduced [on mobile phones], it is not as attractive as it is [online] "(Marine). "On the

VentesPrivées website, the product just appears [suddenly] like that!!" (Ulrike). "I look at the different sections, the website design and the tabs relating to the services" (Karine).

- Hedonic: pleasant/gratifying sensation

- Utilitarian value of shopping

- "I've been shopping online because the store I chose doesn't exist in La Rochelle."
- "Sometimes, you want to read a book, as if you were craving for food. It's now! - "I try to buy useful items, contrary to my husband, who buys for fun on Ebay, -I try to buy useful items, contrary to my husband, who buys for fun on Ebay,
because he is a comic strip collector" (Coralie). "I buy a lot online, but contrary to because he is a comic strip collector" (Coralie). "I buy a lot online, but contrary to
my husband, I don't buy useless things online. I buy a lot of things... but useful things. I only buy useful stuff". (Marie). (Virginie - student). "I buy only online when I don't have any other choice!" (Amandine) "It's some specific stuff that we need to have that we cannot find in La Rochelle so $[\ldots]$ sometimes we need specific stuff for our pub". (Anne-Do).

- "I say to myself that if everyone buys on Amazon, it is the end of the traditional New developing of specific values as characteristics of the retailing" (Ulrike). "I like the convenience stores, and I defend it, and I also refuse ideological dimension of OSE. the self-checkout. Even if I find it convenient, it represents a full-time job taken" Trust and privacy issues were previously identified as the self-checkout. Even if $I$ find it convenient, it represents a full-time job taken Trust and privacy issues were previous

a foreign (German) website" (Monique). ts of OSE.

Unexpected findings concerning trust and privacy issues

- "According to the layout of the website, as a result, we trust it or don't trust it, me, New developing of Politics as shopping values that look at the site and I say to myself [...]. I look at the different sections, the website characterize the ideological dimension of OSE 
website may have an impact on the way I [feel more confident] (Virginie)

- "Cash is better [than electronic payment] we are more aware of spending, maybe

because of the "Monopoly" game when I was a child (Jordan).

- "I never go on foreign or unknown websites. [...] I usually shop on LaRedoute,

Les 3Suisses websites." (Mélie). "I order and buy on big sites, banks, La Redoute, even don't think about it [...]" (Virginie).

- "Yes, me too, I have two email addresses of which one is for the commercial adverts" (Stéphane). "I can manage to cheat on some websites' formulas; for instance, I complete the telephone number field with zeros, and it passes, because there is no control, and after all zeros are numbers!" (Coralie). "Sometimes I cheat on my date of birth, just for the principle in fact! I had not thought of the

telephone number yet! " (Gilles)

Deci sion aid
- Frame of the OSE: usual, at home; multitasking
- Many ways to browse websites
Use of tools

- Shepping practices: tricks to facilitate the shopping
I start with a furniture looking for the best quality-price ratio; so if I need som (Monique).

"It's cool [to shop online] because we are calm and we can do others thing the things, we can visit others websites, compare [...]; sometimes, we can hang aroun the computer, browsing websites, for instance, for what we can buy for Mother's Day. It's a moment of relaxation, of quietness, we can have other activities" (Marine). "I eat, TV on the side, my little cup of cereals, relaxed, like a grandmother here, I'm fine" (Marie-Haud). "I love shopping online because I'm sitting in my chair, at home, I don't have to go away" (Ulrike). "I watch 10 minutes of a movie; then I go to another website" (Marie-Haud). "This is why it takes so much time, because we are not $100 \%$ into it, we are attending to other activities/hobbies" (Camille).

- "When I find a very interesting product or item on an unknown website, I go to search engines to find opinions about the seller" (Gilles). "When I shop online, I have the price comparison tools and several websites opened" (Marie-Haud).

- "I tagged Ventes Privées. I put the website on my bookmarks [...]) I use them [the because I already know them" (Mélie).

"I have watched this site on Youtube" (Virginie - student)

- "You can put something aside for a while, twenty minutes, half an hour" (Sidonie). "I put [products] in the shopping cart, but after that, I remove them! I give up!" (Nicole). "I also put [products] into the shopping cart, and when I feel strong enough, I move on to something else, but when I want to indulge myself, I say: "let's go! Let's order online" (Ulrike). "I never use the shopping cart because when I have enough money to buy it, it isn't for sale anymore!" (Sophie). "It isn't worth using the shopping cart, because in 3 month's time when I return to the website it will not exist anymore!" (Manon).

- "Sometimes, while I chat with my friends, I browse the internet so I can say to my The socialization of the shopping was previously friends: "Hey, look at this gorgeous t-shirt!" and I send to her a link to the website" highlighted in the retailing literature. (Aurélie). Online social interaction on friends

Companions presence: friends, family

their opinion is abts a lot, we ask friends whether you can find it for less, and also what after class, there is no time to go shopping downtown, whereas on the Internet, we can browse the websites all together, to show my friends all the stuff. In front of the screen, we are together; I can show them what stuff I had picked out" (Laurène).

I don't want to buy online.... have to buy a TV set... but I will buy it because some Previous testing of Online reviews in the literature people I know bought one before, as Manu [one of his friends], who is crazy about Online recommendations have been incorporated in the internet, and therefore has experience of it, I'm ready to do it now, even
- Offline decision aid, recommendations (from everyday life)
New developing of direct online social interaction on sociodigital networks

New developing of rituals as a characteristics of the

New dimension in the online context.

ew developing of patronage behavior as a characteristics

New developing of use of shopping tools as a

haracteristics of the pragmatic dimension of OSE

ew developing of shopping practices

revious testing of Online reviews in the literature the social dimension of OSE 
the shopper's age; younger consumers rely on the brands and financial aspect of the transaction whereas older consumers focus on the privacy aspect. They gave different metaphors of risk during the OSE.

It might have been expected that the youngest shoppers - the "digital natives" - should be more familiar with e-commerce and should be more confident while shopping online. However, compared to the older respondents, students from 18 to 20 years old are more cautious in their online behavior. They are followers: they only browse popular websites and buy mainstream brands. Further research is required to investigate such a generational issue.

"Once you are online, you are not safe anymore" (Jordan). Some of the students are afraid to give their credit card number on the Internet. The metaphor used to describe their OSE is the Monopoly game, linked to the arbitrary aspect of the transaction. Indeed, Monopoly is a hazard game. If they consider something to be risky, they resist revealing personal data.

So, instead of fitting the digital native stereotype (Prensky, 2001), the younger respondents showed reluctance and mistrust about online shopping: they do not seem to behave naïvely (Hargittai, 2010).

If the youngest respondents are the most reluctant to give personal data online, older respondents give personal data such as their name, mobile phone number or credit card number. However, they clearly choose the data they reveal; they only give what they consider necessary information and they may lie about other data, such as age or phone number. "I lie on some forms, by giving a wrong phone number. I might only fill it in with zeros, and it is accepted because there is no control. Zeros are ok because they are numbers". (Coralie). "Sometimes, I lie about my date of birth just for fun! I haven't thought about lying with my phone number but next time I will!" (Gilles).

The older consumers are reluctant to give personal information that might be tracked by a "Big Brother" company that might know and misuse their whole data. To lie while filling forms/ questionnaires in this context appears to be rational.

On the other hand, the shopping values that may be observed are tied to the social link created by physical retail stores, and, conversely, to the dematerialization of online shopping. "I guess that if everyone buys on Amazon, it tells the bell of traditional retailing" (Ulrike).

We notice that the underlying value here is more political than the well-known opposition between the retail channels (physical vs. digital retail). The issue for some consumers is to choose retailers which are in accordance with their model of society (local employment, full-time job, human service encounter).

"I like convenience stores, and I even defend them, and I also refuse the digital self-checkout. Even if I find it convenient, it is a full-time job taken" (Nicole). "I am not open to the idea of globalization; I will not find a better price in a foreign (German) website" (Monique).

\subsubsection{The rituals during the OSE}

The OSE usually occurs at home and consumers have rituals performing other activities while shopping.

"It's cool [to shop online] because we are in a quiet, familiar environment and we can do others things simultaneously, like watching TV, drinking an orange juice; we have time to look at everything, we can visit other websites, compare articles [...]; sometimes, we can leave the computer aside, browsing websites, for instance, to find what we can buy for Mother's Day. It's a moment of rest, of quietness, we can do other activities" (Marine). "I go out for a coffee-cigarette (Ulrike). "I eat, watch TV, with my little bowl of cereals next to me, relaxed, like 
a grandmother here, I feel fine" (Marie-Haud). "I love shopping online because I'm sitting in my chair, I'm home, I don't have to go away" (Ulrike). "I watch 10 min of a movie; then I jump to another website" (Marie-Haud). "This is why it takes so much time, because we are not $100 \%$ into it, we are busy doing other activities" (Camille).

Even when the consumer expresses utilitarian values, the OSE is a specific moment: "I take my time; I know that if I only have 5 min between two classes, it's not going to be enough; I know that if I just give a quick glance, it is not going to work" (Jordan).

So, the shopping rituals during the OSE may be commonplace because the digital world is part of the environment. The rituals have previously been found to be components of the consumption experience, linked to the sacred (Belk et al., 1989), to culture (Wallendorf and Arnould, 1991) and to be vectors of interpersonal relationships (Goffman, 1974). The research identifies daily rituals as a paramount component of the ideological dimension of the OSE, thereby extending knowledge into the online context.

\subsection{A pragmatic dimension of the OSE}

The pragmatic dimension of the OSE is mainly distinguished by patronage routines, which are composed of the browsing of websites. It is also characterized by various uses of online tools (browsing tools, search tools, shopping tools, etc.) that are part of specific routines and enable shoppers to patronize shopping websites.

\subsubsection{Patronage routines}

As in traditional "brick and mortar" stores, a variety of patronage behaviors are posited by the consumers. As in the offline context, there are routines in shopping online. Shoppers patronize websites in different ways; they may open different tabs at the beginning of their session: "When I shop online, I have the price comparison tools and several websites open" (Marie-Haud). While they browse the web, they are likely to use bookmarks and browsing histories. For some consumers, the use of a bookmark seems to refer to new websites that consumers are not yet familiar with. "Usually, I don't even mark the websites because I already know them" (Mélie). On the contrary, other consumers state that they always use them for convenience: "I tagged Ventes Privées. I put the website on my bookmarks [...] I use them all the time!" (Jennyfer).

While older respondents "google" the names of websites, products or brands to find websites, the younger consumers go to websites through promotional emails (Laurène, Camille, Lucie).

These routines reveal various shopping practices and may constitute different ways of appropriating the OSE. Patronage routines are only discussed in the consumption experience literature (De Certeau, 1984) and ignored or assimilated to the utilitarian orientation in the online literature; these results highlight their existence and role as components of the pragmatic dimension of the OSE.

\subsubsection{Online routines through online tools}

Browsing and shopping tools are also part of the OSE via specific routines. The virtual shopping cart is an example. Shoppers place items in the online shopping cart to secure online price promotions or to select the items they like. However, they may also place items in it to have fun - and not necessarily to buy the product: "I put the item in the shopping cart, but afterwards, I remove it! I give up!" (Nicole). "I also put [products] into the shopping cart, and when I am strong enough, I move on to something else, but when I want to indulge myself, I say: Let's go! Let's order online" (Ulrike). "I never use the shopping cart because when I have enough money to buy an item, it isn't on sale anymore!" (Sophie). "It isn't worth using the shopping cart, because in 3 months when I go back to the website, the product will not be there anymore!" (Manon).

This routine goes beyond the purchase intention and is really part of the routine of the OSE. These findings are consistent with those of Close and Kukar-Kinney (2010). This contributes to our understanding of the OSE, supporting the role and importance of this component of the pragmatic dimension of the OSE.

\subsection{A social dimension of OSE}

A fourth fundamental dimension of the OSE has been identified through discourse analysis. It refers to a social dimension and covers three different characteristics: direct online social interaction with friends (on socio-digital networks), the companions' presence and online consumer reviews.

\subsubsection{Direct online social interaction with friends on socio-digital networks}

While surfing on e-commerce websites, some consumers indicate that they chat online on Facebook with their "friends" to comment and compare the products they are considering for purchase. They rely on their friends to help them in their decision making. "If something is expensive, we ask friends whether and where you can find it for less, and also what their opinion is about it and whether it's worth buying" (Laurène).

Therefore, they need their peers or family members' opinion on the products they are interested in. For instance, one woman respondent explains that when she browses the fashion websites or fashion accessories websites, she usually shares a link with a friend who is chatting with her (on Facebook) at the same moment. "Sometimes, while I chat with my friends, I browse the internet so I can say to my friends: 'Hey, look at this gorgeous tshirt!' and I send them a link to the website" (Aurélie).

Through these online social interactions, the shopper places his/her decision process within a collective process and into a social consumption framework. This collective process is specific because it is limited to a few close friends connected on Facebook (typically). Furthermore, the results clearly show that female respondents put forward the role of companions (whereas male respondents only refer to consumer reviews and ratings).

This result is remarkable because the academic literature focuses on a specific commercial place (i.e. a shop or a website), a practice which leads us to construe that both online social interaction with friends on Facebook and consumer reviews and ratings can be part of the social dimension of the OSE.

\subsubsection{Companions' presence: including co-presence in the OSE}

During the interviews, consumers also indicated - from time to time - that they shopped online with friends or family members sitting next to them in front of the same screen. "In the evening, after class, we don't have time to go shopping downtown, whereas on the Internet, we can browse the websites together, and I can show my friends all the stuff. In front of the screen, we are together; I can show them what stuff I have picked" (Laurène).

Navigation and the OSE are collective, but in a different sense than the one discussed above. The interaction frame must be widened from the consumer - computer to consumer - friend(s) computer situation. This result is consistent with literature dedicated to traditional shopping (Borges et al., 2010) but has not been considered for the OSE yet. 


\subsubsection{Online consumer reviews: you will never shop alone}

The third component of the social and collective dimension of the OSE refers to a well-known aspect, which has by now been well documented in the literature, that is to say, online customer reviews and product ratings (Chevalier and Mayzlin, 2006; Dellarocas, 2003).

"There are stars and testimonies" (Karine). "There is the number of sales, for example, for sellers; you may check the number of sales and the satisfaction rate" (Coralie). "I look at the number of customers on the website. For instance, if I have the choice, I prefer choosing a website that has the highest number of purchases; it makes me feel secure because 3500 customers is more reassuring than 50!" (Thierry). "When I have found an item but I don't know the website, I try to find opinions on this provider through search engines" (Gilles). Interviews strongly confirm that consumers use online products ratings and comments published online by other consumers while shopping. These reviews are an essential part of the OSE.

\section{Conclusion and future research}

The objective of this research was to explore the content of consumers' experience when they shop online and to focus on the conceptualization of the OSE as a whole. First, an extensive literature review crossing three main fields (i.e. consumption, shopping and online experiences) has been conducted to identify the diverse aspects and concepts of these specific experiences (Table 1). Then, an integrative conceptual framework of the OSE based on the literature review has been proposed (Table 2). It has been tested by the exploring consumer discourses of OSEs through focus groups. Finally, the conceptualization of the OSE has been reshaped and reinforced through the consumers' discourse analysis, and four dimensions have been highlighted and detailed through their characteristics and components (Table 4).

Basically, beyond the extensive literature review proposed in the first part of the paper, this research provides three main contributions.

The first one is the addition of new knowledge to our understanding of the OSE which made us offer a definition of the OSE as a complex experience lived by the consumers when they shop online, in both online and offline contexts (in a specific place, time, with or without any companions' presence...); it is a holistic and subjective process resulting from interactions between consumers, shopping practices (including tools and routines) and the online environment (e.g. shopping websites, online consumer reviews, and social media).

The second main contribution resolves a gap in our knowledge with a detailed conceptualization of the OSE through four core dimensions: the physical, ideological, pragmatic and social dimensions (Table 4). More precisely, the OSE is composed of:

- a physical dimension which involves the consumers' senses exposed to the online context, including time distortion (duration of experience), time pressure, time management, and the sensations and feelings created by the ergonomics and esthetics of the websites (architecture, design and colors),

- an ideological dimension, which involves the consumers' shopping values of the consumers, that is to say hedonic, pleasant or gratifying sensations and utilitarian values, the political issues such as trust and privacy which engage consumers, and the rituals that the multitasking consumers have online.

- a pragmatic dimension involving online patronage, routines and tactics engaged by the consumers in order to plan, search for and purchase. These practices (ways of browsing, use of tools...) are constitutive of the co-creation of the experience and allow the consumers to (re)appropriate the online environment.

- a social dimension, which primarily involves, socialization through the companions' direct presence (friends or family) and online social interaction with friends through socio-digital networks (such as Facebook) and also, 'offline' decision aid, with advice from everyday life as well as online consumer reviews and ratings.

The third main contribution refers more specifically to the components and characteristics of the OSE dimensions, in comparison with the previous literature and the initial conceptual framework.

First of all, this research emphasizes that the OSE, far from being virtual, is embodied by the use of online tools and patronage routines. Thus, the pragmatic dimension of the OSE, which was only considered in the 'offline' consumption experience (Table 1) (De Certeau, 1984; Gentile et al.,. 2007; Heilbrunn, 2010; Holt, 1995; Schmitt, 1999), is clearly highlighted. The results may not confirm the place as a component of the physical dimension. Nevertheless, the shoppers constantly refer to their - online and offline - environment.

Then, specific values composing the ideological dimension of the OSE - values which were not apparent in the literature - have been identified: they refer to the privacy issue and to the political aspect of shopping.

Additionally, the research establishes connections between the flow concept on the one hand, (initially proposed by Hoffman and Novak, 1996 in the online context and reconsidered in the recent literature since then) and on the other hand, the "traditional" dimensions of consumption and shopping experiences. If this research does not support the idea that the OSE may be totally characterized by the state of flow (recent publications on this notion do not consider it neither - cf. supra), two elements of the flow model have nevertheless been confirmed: the time distortion and the sensation of pleasure/gratification. It was not the case for the loss of self-consciousness - which, by definition is hardly identifiable in the consumer interviews.

Finally, the social dimension revealed interesting results. There is a true and genuine social dimension in the OSE (which had not been foreshadowed) which takes a specific form in the online context: thanks to online consumer reviews (as it wasexpected) and thanks to socio-digital networks (Facebook in particular). Far from being confined to social life management and digital identity issues, socio-digital networks are fundamental part of the OSE when they are used to chat with friends while shopping online and to include friends in the shopping (and decision) process and experience.

The main limitation of this research is that, by its exploratory nature, it does not measure the weight of each dimensions of the OSE. In this respect, future research is required in this direction. Second, the focus groups were conducted in France, and there was no comparison with other cultures. Future studies shall examine other populations and cultures. This seems to be particularly important as far as the ideological and the social dimensions are concerned. As the results mainly highlighted original and unexpected results regarding the pragmatic and social dimensions, therefore, we wish to put further emphasis in this direction. More precisely, it seems to be very interesting both in terms of theoretical and managerial implications to extend our knowledge concerning the pragmatic dimension of the OSE (patronage routines and online tools uses) to better understand the appropriation of the online environment by consumers when they shop online. As far as the social dimension is concerned, the integration of social media, especially socio-digital networks, within the consumers' online practices and shopping behaviors appears to be a fertile research direction.

\section{References}

Addis, M., Holbrook, M.B., 2001. On the conceptual link between mass customisation and experiential consumption: an explosion of subjectivity. J. Consum. Behav. 1 (1), 50-66. 
Albrecht, K., 1995. Delivering Customer Value: It's Everyone's Job, vol. 9. Productivity Press, Portland, OR.

Andreu, L., Bigné, E., Chumpitaz, R., Swaen, V., 2006. How does the perceived retail environment influence consumer' emotional experience? Evidence from two retail settings. Int. Rev. Retail, Distrib. Consum. Res. 16 (5), 559-578.

Arnold, M.J., Reynolds, K.E., Ponder, N., Lueg, J.E., 2005. Customer delight in a retail context: investigating delightful and terrible shopping experiences. J. Bus. Res. $58,1132-2245$.

Arnould, E.J., Price, L., 1993. River magic: extraordinary experience and the extended service encounter. J. Consum. Res. 20 (1), 24-45.

Arnould, E.J., Price, L., Zinkhan, G., 2004. Consumers. McGraw-Hill/Irwin, New-York

Arnould, E.J., Thomson, C.J., 2005. Consumer Culture Theory (CCT): twenty years of research. J. Consum. Res. 31, 868-882.

Aubert-Gamet, V., 1997. Twisting servicescapes: diversion of the physical environment in a re-appropriation process. Int. J. Serv. Industry Manag. 8 (1), 26-41.

Babin, B.J., Darden, W.R., Griffin, M., 1994. Work and/or fun: measuring hedonic and utilitarian shopping value. J. Consum. Res. 20, 644-656.

Babin, B.J., Attaway, J.S., 2000. Atmospheric affect as a tool for creating value and gaining share of customer. J. Bus. Res. 49 (2), 91-99.

Bäckström, K, 2011. Shopping as leisure: an exploration of manifoldness and dynamics in consumers shopping experiences. J. Retail. Consum. Serv. 18, 200-209.

Bagdare, S., Jain, R., 2013. Measuring retail customer experience. Int. J. Retail Distrib. Manag. 41 (10), 790-804.

Bart, Y., Shankar, V., Sultan, F., Urban, G.L., 2005. Are the drivers and role of online trust the same for all web sites and consumers? A large-scale exploratory empirical study. J. Mark. 69 (4), 133-152.

Belk, R.W., Wallendorf, M., Sherry Jr., J.F., 1989. The sacred and the profane in consumer behavior: theodicity and the odyssey. J. Consum. Res. 16 (1), 1-38.

Borges, A., Chebat, J.-C., Babin, B., 2010. Does a companion always enhance the shopping experience? J. Retail. Consum. Serv. 17, 294-299.

Brakus, J.J., Schmitt, B.H., Zarantonello, L., 2009. Brand experience: what is it? How is it measured? Does it affect loyalty?. J. Mark. 73 (3), 52-68.

Bridges, E., Florsheim, R., 2008. Hedonic and utilitarian shopping goals: the online experience. J. Bus Res. 61, 309-314.

Carù, A., Cova, B., 2007. Consuming experience: an introduction. In: Carù, A., Cova B. (Eds.), Consuming Experience. Routledge, Abingdon, pp. 3-16.

Chebat, J.-C., Sirgy , J., James, V., 2006. Upscale image transfer from malls to stores: a self-image congruence explanation. J. Bus. Res. 59, 1288-1296.

Chevalier, J.A., Mayzlin, D., 2006. The effect of word of mouth on sales: online book reviews. J. Mark. Res, 43 (3), 345-354.

Corbin, J., Strauss, A., 2008. Basics of Qualitative Research, Techniques and Procedures for Developing Grounded Theory, 3rd ed. Sage Publications, Thousand Oaks, California.

Close, A.G., Kukar-Kinney, M., 2010. Beyond buying: motivations behind consumers online shopping cart use. J. Bus. Res. 63, 986-992.

De Certeau, M., 1984. The practice of Everyday Life. University of California Press Berkeley.

Dellarocas, C., 2003. The digitization of word of mouth: promise and challenges of online feedback mechanisms. Manag. Sci. 49 (10), 1407-1424.

Dubé, L., LeBel, J.L., 2003. The content and structure of laypeople's concept of pleasure. Cognit. Emot. 17 (3), 263-296.

Edgell, S., Hetherington, K., Warde, A., 1997. In: Edgell, et al. (Eds.), Consumption Matters: the Production and Experience of Consumption. Blackwell, Oxford.

Fiore, A.M., Kim, J., 2007. An integrative framework capturing experiential and utilitarian shopping experience. Int. J. Retail Distrib. Manag. 35 (6), 421-442.

Firat, A.F., Dholakia, N., 1998. Consuming people: from political economy to theaters of consumption. Routledge, London.

Fischer, G.N., 1997. La psychologie sociale, Point, Seuil.

Füller, J.G., Jawecki, G., Mühlbacher, H., 2007. Innovation creation by online basketball communities. J. Bus. Res. 60 (1), 60-71.

Gentile, C., Spiller, N., Noci, C., 2007. How to sustain the customer experience: an overview of experience components that co-create value with the customer. Eur. Manag. J. 25 (5), 395-410.

Goffman, E., 1974. Frame Analysis: an Essay on the Organization Experience. Harper \& Row, New York.

Hargittai, E., 2010. Digital na(t)ives? Variation in Internet skills and uses among members of the "Net generation". Sociological Inquiry, LXXX 1.

Heilbrunn, B., 2010. La consommation et ses sociologies, 2nd ed. A. Colin, Paris.

Hoffman, D.L., Novak, T.P., 1996. Marketing in hypermedia computer-mediated environments: conceptual foundations. J. Mark. 60 (3), 50-68.

Hoffman, D.L., Novak, T.P., 2009. Flow online: lessons learned and future prospects. J. Interact. Mark. 23 (1), 23-34.

Holbrook, M., 2006. The consumption experience - something new, something old, something borrowed, something sold: Part 1. J. Macromark. 26 (2), $259-266$.

Holbrook, M.B., 2000. The millennial consumer in the texts of our time: experience and entertainment. J. Macromark. 20 (2), 178-192.

Holbrook, M., Hirschman, E., 1982. The experiential aspects of consumption. J. Consum. Res. 9, 132-140.

Holt, D.B., 1995. How consumers consume: a typology of consumption practices. J. Consum. Res. 22, 1-16.

Holzwarth, M., Janiszewski, C., Neumann, M.M., 2006. The influence of avatars on online consumer shopping behavior. J. Mark. 70 (4), 19-36.

Hui, M.K., Bateson, J.E.G., 1991. Perceived control and the effect of crowding and consumer choice on the service experience. J. Consum. Res. 18, 174-184.
Jüttner, U., Schaffner, D., Windler, K., Maklan, S., 2013. Customer service experiences. Developing and applying a sequential incident laddering technique. Eur. J. Mark. 47 (5/6), 738-768.

Kohler, T., Fueller, J., Matzler, K., Stieger, D., 2011. Co-creation in virtual worlds: the design of the user experience. MIS Q. 35 (3), 773-788.

Kozinets, R.V., 2002. The field behind the screen: using netnography for marketing research in online communities. J. Mark. Res. 39, 61-72.

Kozinets, R.V., Hemetsberger, A., Schau, H.J., 2008. The wisdom of consumer crowds: collective innovation in the age of networked marketing. J. MacroMark. 28, 339-354.

Lemke, F., Clark, M., Wilson, H., 2011. Customer experience quality: an exploration in business and consumer contexts using repertory grid technique. J. Acad. Mark. Sci. 39 (6), 846-869.

Machleit, K.A., Eroglu, S.A., 2000. Describing and measuring emotional response to shopping experience. J. Bus. Res. 49, 101-111.

Mandel, N., Johnson, E., 2002. When web pages influence choice: effects of visual primes on experts and novices. J. Consum. Res. 29 (2), 235-245.

Mathwick, C., Rigdon, E., 2004. Play, flow, and the online search experience. J. Consum. Res. 31 (2), 324-332.

Mathwick, C., Malhotra, N., Rigdon, E., 2001. Experiential value: conceptualization, measurement and application in the catalog and Internet shopping environment. J. Retail. 77, 39-56.

McCracken, G., 1986. Culture and consumption: a theoretical account of the structure and movement of the cultural meaning of consumer goods. J. Consum. Res. 13, 71-84.

Michaud-Trévinal, A., Stenger, T., 2012. Online shopping experiences: the use and appropriation of commercial websites through a qualitative survey carried out in France. In: Proceedings of the 41th Annual Conference of the Academy of Marketing Science. May 16-19, New Orleans, USA

Miles, M.B., Huberman, A.M., 1984. Qualitative data analysis: a sourcebook of new methods. Sage Publications, Thousand Oaks, California.

Moisander, J., Peñaloza, L., Valtonen, A., 2009. From CCT to CCC, Building consumer culture community, In: Sherry, J.F. Fischer, E. (Eds.), Explorations of Consumer Culture Theory. Routledge, New York, pp. 7-33

Muniz Jr., A.M., O'Guinn, T.C., 2011. Brand community. J. Consum. Res. 27 (4), 412-432.

Nambisan, P., Watt, J.H., 2011. Managing customer experiences in online product communities. J. Bus. Res. 64, 889-895.

Novak, T.P., Hoffman, D.L., Duhacheck, A., 2003. The influence of goal-directed and experiential activities on online flow experiences. J. Consum. Psychol. 13 (1 and 2), 3-16.

Novak, T.P., Hoffman, D.L., Yung, Y.-F., 2000. Measuring the customer experience in online environments: a structural modeling approach. Mark. Sci. 19 (1), 22-42.

Pelet, J.-E., Papadopoulou, P., 2012. The effect of colors of e-commerce websites on consumer mood, memorization and buying intention. Eur. J. Inform. Syst. 21, 438-467.

Pentina, I., Amialchuk, A., Taylor, D.G., 2011. Exploring effects of online shopping experiences on browser satisfaction and e-tail performance. Int. J. Retail and Distrib. Manag. 39 (10), 742-758.

Pine, B.J., Gilmore, J., 1999. The experience economy: work is theatre and every business a stage. HBS Press, Harvard.

Prensky, M., 2001. Digital natives, digital immigrants, part 1, On the Horizon, IX, 5,

Price, L.L., Arnould, E., Tierney, P., 1995. Going to extremes: managing service encounters and assessing provider performance. J. Mark. 59 (2), 83-97.

Rook, D.W., 1985. The ritual dimension of consumer behavior. J. Consum. Res. 12, 251-264.

Rompay, T.J.L., Krooshoop, J., Verhoeven, J.W.M., Pruyn, Ad T.H., 2012. With or without you: interactive effects of retail density and need for affiliation on shopping pleasure and spending. J. Bus. Res. 65, 1126-1131.

Rose, S., Clarck, M., Samouel, P., Hair, N., 2012. Online customer experience in eretailing: an empirical model of antecedents and outcomes. J. Retail. 88 (2), 308-322.

Schau, H.J., Muñiz, A.M., Arnould, J., 2009. How brand community practices create value. J. Mark. 73, 30-51.

Schmitt, B.H., 1999. Experiential marketing. NY: Free Press, New York.

Soopramanien, D.G.R., 2011. Conflicting attitudes and scepticism towards online shopping: the mediating role of experience. Int. J. Consum. Stud. 35 (3), 338-347.

Spena, T.R., Caridà, A., Colurcio, M., Melia, M., 2012. Store experience and cocreation: the case of temporary shop. Int. J. Retail Distrib. Manag. 40 (1), 21-40.

Stenger, T., 2011a. Achat et Internet. In: Stenger, T., Bourliataux-Lajoinie, S. EMarketing \& E-Commerce - Concepts, Outils, Pratiques. Coll. Management Sup, Dunod, pp. 249-288.

Stenger, T., 2011b. La prescription de l'action collective - double stratégie d'exploitation de la participation sur les réseaux socionumériques. Hermès, vol. 59, avril, CNRS, pp. 127-133.

Stenger, T., Coutant, A., 2013. Médias sociaux: clarification et cartographie - pour une approche sociotechnique. Déc. Mark. 70, 107-117.

Sweeney, J.C., Soutar, G.N., Johnson, L., 1999. The role of perceived risk in the qualityvalue relationship: a study in a retail environment. J. Retail. 75-105 (1), 77.

Sweeney, J.C., Soutar, G.N., 2001. Consumer perceived value: the development of a multiple item scale. J. Retail. 77 (2), 203-220.

Tauber, E.M., 1972. Why do people shop? Mark. Manag. 4 (2), 58-60.

Verhoef, P.C., Lemon, K.N., Parasuraman, A., Roggeveen, A., Tsiros, M., Schlesinger, L. A., 2009. Customer experience creation: determinants, dynamics and management strategies. J. Retail 85 (1) 31-41. 
Wallendorf, M., Arnould, E., 1991. We gather together: consumption rituals of Thanksgiving day. J. Consum. Res. 18 (June), 13-31.

Woodward, M.N., Holbrook, M.B., 2013. Dialog on some concepts, definitions and issues pertaining to 'consumption experiences'. Mark. Theory 13 (3), 323-344. Yoon, S.-J., 2013. Antecedents and consequences of in-store experiences based on an experiential typology. Eur. J. Mark. 47 (5/6), 693-714.
Zaglia, M.E., 2013. Brand communities embedded in social networks. J. Bus. Res. 66 $216-223$.

Zola, E., 1883. Au Bonheur des Dames, Charpentier, translated as The Ladies' Paradise by Brian Nelson (1995). 